\title{
A new look at Old Fourlegs
}

\section{BOOK TITLE:}

The annotated Old Fourlegs: The updated story of the coelacanth

\section{BOOK COVER:}

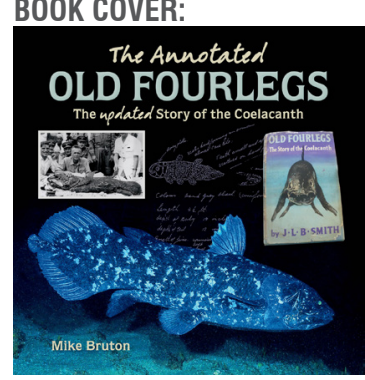

AUTHOR:

Mike Bruton

ISBN:

9781775844990 (softcover)

\section{PUBLISHER:}

Struik Nature, Cape Town; ZAR350

\section{PUBLISHED:}

2017

\section{REVIEWER:}

Brian W. van Wilgen

\section{AFFILIATION:}

Centre for Invasion Biology, Department of Botany and Zoology, Stellenbosch University, Stellenbosch, South Africa

\section{EMAIL:}

bvanwilgen@sun.ac.za

\section{HOW TO CITE:}

Van Wilgen BW. A new look at Old Fourlegs. S Afr J Sci. 2018;114(5/6), Art. \#a0269, 1 page. http://dx.doi. org/10.17159/sajs.2018/a0269

\section{PUBLISHED:}

30 May 2018
The discovery in 1938 of a coelacanth off the coast of East London was an event of immense importance to biological science. Up until then, coelacanths were only known from fossil records, and were believed to have been extinct for 66 million years. The discovery was akin to, for example, finding a pterodactyl flying around the Karoo. Old Fourlegs is a book, published in 1956, that recounts the story of the discovery of the first coelacanth, and the subsequent search, over 14 years, that led to the location and acquisition of a second specimen from the Comoro Islands. And what a dramatic tale it is. The fact that the first fish was captured at all is remarkable. A series of equally unlikely events followed. It was brought to the attention of the young local museum curator (Marjorie Courtenay-Latimer), who recognised it as highly unusual. She managed to convey this to a local chemistry lecturer and part-time ichthyologist (J.L.B. Smith) who was away on an end-of-year fishing holiday, and between them they managed to secure the specimen, so that it could later be adequately described. That these connections were made over the Christmas to New Year period, with everyone on holiday, and with the rudimentary communications technology of the 1930s, is almost miraculous. It changed the course of ichthyology in South Africa, and allowed J.L.B. Smith to focus on laying a solid foundation in that branch of science. The story of the location and retrieval of the second coelacanth 14 years later is even more dramatic. It too was discovered in a remote place (Anjouan Island in the Comoros) at the end of the year, when everyone was on holiday. Smith managed to locate and contact the Prime Minister of South Africa (D.F. Malan), and persuade him to place an Air Force Dakota and crew at his disposal to retrieve the specimen. They proceeded, essentially unannounced, across Portuguese East Africa to the Comoros, where they snatched the specimen from under the noses of the French government, and brought it back to South Africa. It is one of the most exciting scientific adventures I have ever read.

Mike Bruton's publication is a facsimile reproduction of the 1956 first edition of Old Fourlegs, with (as the title suggests) many anecdotes and updates. In itself, Old Fourlegs is a remarkable book. Following its publication in 1956, Old Fourlegs rapidly became an international best-seller and one of the most popular scientific books worldwide at the time. It has appeared in six further English editions, and has been translated into French, German, Russian, Estonian, Afrikaans, Dutch, Slovak, Latvian and Japanese. As a student of J.L.B. Smith, and having gone on to become Director of the (then) J.L.B. Smith Institute of Ichthyology, Mike Bruton is exceptionally well placed to compile the anecdotes and updates.

The annotations themselves, and there are many, provide fascinating insights as well as trivia (e.g. the nickname for the Dakota that was dispatched to collect the coelacanth from the Comoros was the 'Flying Fishcart', and it is now in the South African Air Force Museum at Ysterplaat). The characters involved are also fascinating. Anyone who reads the original book will realise that J.L.B. Smith had little time for J.C. Smuts, a prime minister who had refused him help at one stage, but a lot of respect for D.F. Malan, who did help him. The difference of approach between these two politicians also seems out of character, as Smuts was a scientist and a liberal, while Malan was a conservative theologian and creationist. That help came from the latter and not the former was therefore surprising. Mike Bruton speculates that because Smuts' rapport with nature was rooted in botany and mountains, he probably 'lacked empathy for aquatic life, as if rivers and oceans were on another planet'. Unlike Malan, Smuts was also inclined to accord more respect to foreign scientists than to scientists (and other experts) from his own country. Smith placed his second coelacanth in the genus Malania out of gratitude to Malan, although it was later confirmed that it was in fact the same species as the first one. Another detail that I had not noticed before concerns Smith's monumental work The Sea Fishes of Southern Africa, which first appeared in 1949, and has been updated and republished many times. The more recent titles were Smith's Sea Fishes (1977) and Smiths' Sea Fishes (1986), and our attention is brought to the subtle shifting of the apostrophe in order to correctly recognise that the second work embodies the substantial contributions of J.L.B. Smith's wife Margaret both as an illustrator and a fish taxonomist. Today we know that there are two species of living coelacanths - the original Latimeria chalumnae (widespread in the western Indian Ocean) and L. menadoensis (discovered in a fish market in Indonesia in 1997). Interestingly, no coelacanth has ever been caught on purpose by Western scientists, despite multimillion dollar efforts to do so.

If you have not yet read the original Old Fourlegs, then obtaining a copy of Bruton's book is worth it for that reason alone. But this book is a whole lot more. There are notes and photographs next to each reproduced page, each providing additional insights, updates, or comparisons of modern understanding to predictions put forward in 1956. Finally, the book also contains a biography of J.L.B. Smith, a publication history of Old Fourlegs, as well as of other books on coelacanths, and other books written by J.L.B. Smith. In addition, there is a chapter that provides an overview of coelacanth discoveries, coelacanth biology, and coelacanth conservation, and a further chapter on the significance of the coelacanth in science, culture and art. I would recommend this book unreservedly to anyone with an interest in fish, history or adventure. 